\title{
Science-to-action through global and regional biochar networks
}

\author{
Johannes Lehmann ${ }^{1}$ (]) \\ Received: 17 October 2019 / Accepted: 11 November 2019 / Published online: 29 November 2019 \\ (c) Shenyang Agricultural University 2019
}

Sustainable solutions to the plethora of environmental issues facing us today require sound science as well as actionable technology that is affordable and equitable. Broader awareness of biochar systems emerged from insights of historical soil management of Amerindian populations who modified their soils to remain fertile for centuries, pointing at sustainable improvement of soil functions through biochar additions. This insight alone may remain inconsequential for sustainable development without probing the translation into modern-day realities. To negotiate viable technologies and management that work today and in the future, science has to engage in constant conversation with stakeholders. Here I argue for the importance of local, regional, national and global networks to serve as platforms to foster the translation of science to action, especially, but not limited to, biochar research, development and deployment.

Biochar systems have been probed for their utility to sustainably manage soil fertility; to reclaim degraded or polluted soil; to substitute unsustainable potting media such as mined peat; to mitigate climate change by removing atmospheric carbon dioxide and reducing greenhouse gas emissions from renewable energy; to aid in waste recycling; and to reduce water pollution, among others. The viability of such approaches rests on advancing fundamental science that demonstrates unique advantages of the material properties of biochar and the system-level integration of waste recycling and energy production over existing or projected technologies. Founding a journal such as Biochar is a testament to the interest and need expressed by the scientific community to provide a publication outlet specifically on biochar that broadly captures the science and technology of such systems. However, reaching the sustainability outcomes mentioned above equally hinges on factors that are entirely outside the science domain. Local adoption, political

\section{Johannes Lehmann}

CL273@cornell.edu

1 Soil and Crop Sciences, School of Integrative Plant Science, Cornell University, Ithaca, NY 14853, USA support, or industry development still require individual and context-specific valuation of biochar systems against all other avenues one may want and should explore. Translating science into action and adoption rests on close collaboration between the scientific community and those implementing the technology. This essential conversation greatly benefits from a platform that allows familiarizing oneself with the needs and capabilities across sectoral divides.

Local to global biochar networks (https://biochar-inter national.org/regional/) are geared up to fill this role and have been essential in shaping the discourse between science, industry, policy, and application of biochar for the past 15 years. In addition to moving into unchartered territory, science is well advised to respond to development and deployment needs. This means aligning science programs with the needs of farmers, industry and policy makers. Conversely, policy and industry must base the development and deployment of biochar systems on sound science. Consumer confidence and delivery on product promise, avoiding unintended consequences, and optimization of a portfolio of options has to rely on fundamental insights in how biochar works in soil and other media, as well as life-cycle outcomes of biochar systems. With a widening and at the same time deepening scientific field as well as an emergent industry around biochar, challenges may intensify between the need to strengthen fundamental knowledge and to develop an industry. Cross-sectoral networks may help in minimizing such challenges.

For such networks to be effective in fostering scienceto-action, they need buy-in and support from all constituents. To ensure sustainable development of biochar systems, these networks must be supported by scientific institutions, individual leaders in science, as well as young professionals and students. This support will need to include critical input to documents that provide scientific guidance as well as advice to practical guides for soil managers and strategic guidance for policy makers, but first of all, an open channel for discussion to promote science-to-action. I do encourage you to engage. 